\title{
PREVALENCE OF CARDIOVASCULAR RISK FACTORS IN RELATION TO METABOLIC SYNDROME IN THE ROMA POPULATION COMPARED WITH THE NON-ROMA POPULATION IN THE EASTERN PART OF SLOVAKIA
}

\author{
Ján Fedačko ${ }^{1}$, Daniel Pella ${ }^{1}$, Peter Jarčuška', Leonard Siegfried², Martin Janičko', Eduard Veselíny ${ }^{1}$, Jozef \\ Pella $^{1}$, František Sabol ${ }^{3}$, Pavol Jarčuška ${ }^{4}$, Mária Mareková5, Andrea Madarasová Gecková6, ${ }^{12}$, Peter Pažinka ${ }^{7}$, \\ Monika Jankajová 8 , Ján Kmec ${ }^{9}$, Marián Babčák ${ }^{9}$, Peter Kalanin ${ }^{10}$, Sylvia Dražilováa ${ }^{11}$, Ingrid Babinská12, Beáta \\ Čečetková13 ${ }^{3}$; HepaMeta Team* \\ ${ }_{11}^{1}$ st Department of Internal Medicine, P. J. Šafárik University in Košice, Faculty of Medicine and L. Pasteur University Hospital, Košice, Slovakia \\ ${ }^{2}$ Department of Medical Microbiology, P. J. Šafárik University in Košice, Faculty of Medicine and L. Pasteur University Hospital, Košice, Slovakia \\ ${ }^{3}$ Department of Cardiosurgery, Eastern Slovak Cardiovascular Institute, Košice, Slovakia \\ ${ }^{4}$ Department of Infectious Diseases, P. J. Šafárik University in Košice, Faculty of Medicine and L. Pasteur University Hospital, Košice, Slovakia \\ ${ }^{5}$ Department of Medical Biochemistry, P. J. Šafárik University in Košice, Faculty of Medicine and L. Pasteur University Hospital, Košice, Slovakia \\ ${ }^{6}$ Olomouc University Social Health Institute, Palacký University in Olomouc, Olomouc, Czech Republic \\ ${ }^{71}$ st Department of General Surgery, P. J. Šafárik University in Košice, Faculty of Medicine and L. Pasteur University Hospital, Košice, Slovakia \\ ${ }^{8}$ Department of Cardiology, Eastern Slovak Cardiovascular Institute, Košice, Slovakia \\ ${ }^{9}$ Department of Cardiology and General Internal Medicine, J. A. Reiman Hospital, Prešov, Slovakia \\ ${ }^{10}$ Department of Family Medicine, P. J. Šafárik University in Košice, Faculty of Medicine and L. Pasteur University Hospital, Košice, Slovakia \\ ${ }^{11}$ Department of Internal Medicine, Poprad Hospital, Poprad, Slovakia \\ ${ }^{12}$ Health Psychology Unit, Department of Public Health, Faculty of Medicine, P. J. Šafárik University in Košice, Košice, Slovakia \\ ${ }^{13}$ Department of Epidemiology, Faculty of Military Health Sciences, University of Defence, Hradec Králové, Czech Republic
}

\section{SUMMARY}

Background: Obesity-induced metabolic syndrome is a multiple risk factor for cardiovascular (CV) risk factors and type 2 diabetes, and ethnic minorities seem to have unfavourable medical risk factors in general more frequently than majority populations.

Objective: The aim of this study was to evaluate the prevalence of cardiovascular risk factors in relation to metabolic syndrome in the Roma population compared with the non-Roma population residing in the eastern part of Slovakia.

Results: 123 Roma and 79 non-Roma patients with metabolic syndrome were evaluated. Men between 40-55 years of age had 4.76-times higher odds and women 5.26-times higher odds for metabolic sydrome compared with the younger population. We found statistically significant higher waist circumference in the Roma subpopulation and higher body mass index as well, although in selected population with metabolic syndrome. HDL cholesterol was significantly lower in both Roma men and women, and LDL cholesterol was not significant in men and women with metabolic syndrome. Triglycerides levels were significantly higher in non-Roma women only. High-sensitivity C-reactive protein (hsCRP) values were not in correlation with age but were associated with the increasing number of fulfilled criteria for metabolic syndrome in both subgroups (Roma, non-Roma), independently of gender.

Conclusion: Our study confirmed higher prevalence of obesity, metabolic syndrome and other $\mathrm{CV}$ risk factors associated with metabolic syndrome among younger Roma population, which may be associated with increased cardiovascular disease (CVD) morbidity and mortality among elderly Roma compared with non-Roma.

Key words: metabolic syndrome, Roma population, cardiovascular risk factors, obesity, dyslipidemia, inflammation

Address for correspondence: D. Pella, 1st Department of Internal Medicine, P. J. Šafárik University in Košice, Faculty of Medicine and L. Pasteur University Hospital, Tr. SNP 1, 04011 Košice, Slovakia. E-mail: daniel.pella@upjs.sk

\section{INTRODUCTION}

Metabolic syndrome, a concurrence of disturbed glucose and insulin metabolism, overweight and abdominal fat distribution,

\footnotetext{
*HepaMeta Team members are listed in Appendix
}

mixed dyslipidemia and hypertension, may cause the subsequent development of type 2 diabetes mellitus and cardiovascular disease (CVD) $(1,2)$. Obesity-induced metabolic syndrome is a multiple risk factor for CVD and type 2 diabetes. Several recent reports (3-6) indicate that the presence of metabolic syndrome is associated with increased risk for both CVD and type 2 diabe- 
tes. Individuals with metabolic syndrome have at least a 2-fold increased risk for CVD compared with those without metabolic syndrome and there is a 5 -fold increased risk for type 2 diabetes in both men and women (7). The risk for diabetes is the highest in those with impaired fasting glucose, or impaired glucose tolerance (IGT). Once a patient develops type 2 diabetes, risk for CVD is enhanced. Not only relative risk for coronary heart disease (CHD) is increased by 2 - to 3 -fold, but once CHD becomes manifest in a patient with diabetes, the prognosis for survival is greatly reduced (8).

Early identification, treatment and prevention of metabolic syndrome represent a major challenge for health care professionals in the face of obesity epidemic and sedentary lifestyle (6). Obesity induced metabolic syndrome is associated with vascular inflammation which plays a pivotal role in all phases of atherosclerosis progression. High-sensitivity C-reactive protein (hsCRP), one of the most studied biomarkers of inflammation, is an independent predictor of future cardiovascular events and can add further insight to risk stratification. Assessment of hsCRP levels in clinical practice is feasible and inexpensive (9).

Ethnic minorities seem to have generally unfavourable medical risk factors more frequently than majority populations $(10,11)$. One of the largest minority groups in Central and Eastern Europe is the Roma population. In Slovakia, Roma are considered to be the second largest minority group (12). According to professional demographic estimates, approximately 430,000 Roma live in Slovakia, which represents $8 \%$ of the total population of the country (13). Previous studies have found higher mortality rates and lower life expectancy of Roma than non-Roma $(14,15)$.

The aim of this study was to evaluate prevalence of CV risk factors in relation to metabolic syndrome in the Roma population compared with the non-Roma population in the eastern part of Slovakia.

\section{MATERIALS AND METHODS}

The sample consisted of 452 Roma (mean age $=34.7 ; 35.2 \%$ men) and 403 non-Roma (mean age $=33.5 ; 45.9 \%$ men) respondents. Roma in selected settlements were recruited by local Roma community workers. Respondents from major population were randomly selected from a list of patients from general practitioners. Data were collected via questionnaire, anthropometric measures and blood sample analyses. Clinical biochemistry tests for determination substrates: glucose, proteins (hs-CRP as risk factor), enzymes (gamma-glutamyl transferase-GGT) and lipid parameters (triacylglycerols - TAG or TG, total cholesterol TC, HDL cholesterol - HDL-C, LDL cholesterol - LDL-C). All biochemical parameters were determined by routine biochemical methods on analyser ADVIA 2400 or 1650. Excessive alcohol use was defined as an intake of over $20 \mathrm{~g}$ of alcohol daily on average, based on answers in the questionnaire, and those patients were excluded. The methodology is described in detail elsewhere (16).

\section{Statistical Analysis}

Categorical data are presented in absolute counts and percentages; interval data are presented as the median (interquartile range) because of nonparametric distribution. Measurement of the statistical significance of differences between categorical data was performed by chi-square test, and for interval data using the Mann-Whitney U test.

\section{RESULTS}

In this observational study we examined a total of 420 Roma participants and 382 non-Roma participants. The basic characteristics of the study cohort are shown in Table 1. Roma men and women had statistically significant lower mean plasma levels of total cholesterol, HDL cholesterol and the plasma level of uric acid as well. Roma women had significantly higher waist circumference and body mass index overall compared with not significant findings in the male population. Overweight significance for Roma-women ( $53.4 \%$ of all Roma women) was already found and first-grade obesity was significant in the whole Roma study cohort (Roma men $28.8 \%$, Roma women $26.2 \%$ ) compared with non-Roma. The level of hsCRP was statistically significantly higher for both Roma men and Roma women, but did not achieve significance as a risk factor for cardiovascular disease. Plasma levels of triglycerides, mean age, glucose, and blood pressure were not significantly different among all groups. LDL cholesterol as a risk factor for CV disease was statistically higher only in non-Roma men. Smoking was frequently (significantly higher) reported for both genders of the Roma population. The prevalence of metabolic syndrome was also found to be higher in the Roma population.

Out of this study cohort we selected 123 Roma and 79 nonRoma patients with metabolic syndrome for further evaluation (Table 2). Lipid profile analyses show that HDL cholesterol remains statistically lower for both Roma men and women and that values of LDL cholesterol were not significantly different in both men and women with metabolic syndrome compared with the whole study cohort. Triglycerides were significantly higher in non-Roma women only. Although selecting a subpopulation with documented metabolic syndrome, we found statistically significant higher waist circumference for the Roma subpopulation and higher body mass index as well. We found that the prevalence of metabolic syndrome in the examined population was associated with advanced age. Men between 40-55 years of age had 4.76-times higher odds and women had 5.26-times higher odds for metabolic sydrome compared with the younger population. Ethnicity did not play a role at all (Table 3 ). We analysed a specific gender comparison of the individual metabolic syndrome components between participants with/without metabolic syndrome in the Roma population (Table 4, 5) and we found that plasma glucose levels, plasma triglycerides levels, plasma HDL cholesterol levels, waist circumference, and systolic blood pressure were significantly different in the Roma population with metabolic syndrome (all representing higher cardiovascular risk). There were no statistical differences in smoking habits among the Roma subgroup with metabolic syndrome.

Focusing on inflammation (hsCRP), we found highly statistically significant results for the Roma population with metabolic syndrome, especially in Roma men (Table 2, 5). We found that the elevation of hsCRP was not in correlation with age but was associated with increasing number of fulfilled criteria for metabolic 
Table 1. Parameters of the study cohort. Presented as median (IQR), BMI, smoking, MS as percentage

\begin{tabular}{|c|c|c|c|c|c|c|}
\hline & $\begin{array}{c}\text { Roma men } \\
\mathrm{N}=159\end{array}$ & $\begin{array}{c}\text { Non-Roma men } \\
\quad \mathrm{N}=181\end{array}$ & $p$ & $\begin{array}{l}\text { Roma women } \\
\qquad \mathrm{N}=261\end{array}$ & $\begin{array}{l}\text { Non-Roma women } \\
\qquad \mathrm{N}=201\end{array}$ & $p$ \\
\hline Age & $35.1(15.83)$ & $33.7(11.0)$ & ns & $35.5(14.9)$ & $34.2(11.0)$ & ns \\
\hline Cholesterol & $4.64(1.26)$ & $5.09(1.34)$ & $<0.001$ & $4.73(1.2)$ & $5.06(1.15)$ & $<0.001$ \\
\hline LDL & $2.34(0.96)$ & $2.69(1.01)$ & 0.001 & $2.52(0.86)$ & $2.51(0.83)$ & ns \\
\hline $\mathrm{HDL}$ & $0.95(0.37)$ & $1.15(0.34)$ & $<0.001$ & $1.11(0.34)$ & $1.38(0.47)$ & $<0.001$ \\
\hline TG & $1.14(0.84)$ & $1.08(0.80)$ & ns & $1.02(0.74)$ & $0.92(0.69)$ & ns \\
\hline ApoB100 & $0.72(0.32)$ & $0.78(0.33)$ & ns & $0.74(0.27)$ & $0.72(0.27)$ & ns \\
\hline UA & $164.0(35.7)$ & $310.1(120.9)$ & $<0.001$ & $195.0(81.9)$ & $223.0(84.3)$ & 0.002 \\
\hline Glu & $4.83(0.74)$ & $4.86(0.71)$ & ns & $4.61(0.74)$ & $4.72(0.6)$ & ns \\
\hline Waist & $90.0(22)$ & $92.0(16)$ & ns & $87.0(19)$ & $80.2(17)$ & $<0.001$ \\
\hline BMI & $26.3(8.44)$ & $25.5(5.98)$ & ns & $25.5(8.06)$ & $22.9(6.13)$ & $<0.001$ \\
\hline sBP & $126.0(20)$ & $124.0(18)$ & ns & $116.0(18)$ & 116.7 (18) & ns \\
\hline $\mathrm{dBP}$ & $75.7(17)$ & $75.3(12)$ & ns & $72.0(14)$ & $75.0(13)$ & 0.009 \\
\hline hsCRP & $1.91(3.91)$ & $0.95(1.48)$ & $<0.001$ & $1.52(3.07)$ & $0.93(2.45)$ & 0.045 \\
\hline $\mathrm{BMI}>30$ & $28.8 \%$ & $16.3 \%$ & 0.005 & $26.2 \%$ & $11.0 \%$ & $<0.001$ \\
\hline $\mathrm{BMI}>25$ & $55.8 \%$ & $54.3 \%$ & ns & $53.4 \%$ & $34.9 \%$ & $<0.001$ \\
\hline Smoking & $62.9 \%$ & $34.6 \%$ & $<0.001$ & $26.2 \%$ & $11.0 \%$ & $<0.001$ \\
\hline MS & $29.7 \%$ & $20.5 \%$ & 0.049 & $29.6 \%$ & $19.6 \%$ & 0.011 \\
\hline
\end{tabular}

IQR - interquartile range

Table 2. Parameters of the study cohort with metabolic syndrome. Presented as median (IQR), BMI, smoking as percentage (n).

\begin{tabular}{|l|c|c|c|c|c|c|}
\hline & $\begin{array}{c}\text { Roma men } \\
\mathrm{n}=47\end{array}$ & $\begin{array}{c}\text { Non-Roma men } \\
\mathrm{n}=38\end{array}$ & $\mathbf{p}$ & $\begin{array}{c}\text { Roma women } \\
\mathrm{n}=76\end{array}$ & $\begin{array}{c}\text { Non-Roma women } \\
\mathrm{n}=41\end{array}$ & $\mathrm{p}$ \\
\hline Age & $40.4(10.8)$ & $36.7(9.5)$ & $\mathrm{ns}$ & $42.5(9.8)$ & $39.8(8.1)$ & $\mathrm{ns}$ \\
\hline Cholesterol & $4.90(1.59)$ & $5.67(1.43)$ & $\mathrm{ns}$ & $5.09(1.26)$ & $5.60(1.63)$ & $\mathrm{ns}$ \\
\hline LDL & $2.58(1.07)$ & $3.02(0.99)$ & $\mathrm{ns}$ & $2.76(0.85)$ & $3.12(1.07)$ & $\mathrm{ns}$ \\
\hline HDL & $0.79(0.21)$ & $1.00(0.23)$ & 0.003 & $0.97(0.25)$ & $1.08(0.28)$ & 0.010 \\
\hline TG & $2.10(1.61)$ & $2.05(1.16)$ & $\mathrm{ns}$ & $1.70(0.86)$ & $1.93(1.21)$ & 0.002 \\
\hline ApoB100 & $0.84(0.36)$ & $0.93(0.36)$ & $\mathrm{ns}$ & $0.85(0.26)$ & $0.92(0.36)$ & $\mathrm{ns}$ \\
\hline UA & $292(147)$ & $355(88)$ & $\mathrm{ns}$ & $212(103)$ & $245(83)$ & 0.004 \\
\hline Glu & $5.19(1.26)$ & $5.27(0.88)$ & $\mathrm{ns}$ & $4.97(0.95)$ & $4.86(0.74)$ & $\mathrm{ns}$ \\
\hline Waist & $109.5(17)$ & $103.0(10)$ & 0.003 & $96.0(14)$ & $95.0(17)$ & 0.005 \\
\hline BMl & $31.6(7.41)$ & $29.7(4.16)$ & 0.001 & $30.8(5.83)$ & $29.1(5.62)$ & 0.003 \\
\hline SBP & $136(20)$ & $132(56)$ & $\mathrm{ns}$ & $131(27)$ & $130(24)$ & $\mathrm{ns}$ \\
\hline dBP & $85(18)$ & $84(11)$ & $\mathrm{ns}$ & $84(15)$ & $83(12)$ & $\mathrm{ns}$ \\
\hline hsCRP & $4.70(3.93)$ & $1.40(2.09)$ & $<0.001$ & $2.68(5.24)$ & $2.26(6.31)$ & $<0.001$ \\
\hline BMl > 30 & $68.1 \%(32)$ & $47.4(18)$ & 0.054 & $54.2 \%(45)$ & $41.5 \%(17)$ & $\mathrm{ns}$ \\
\hline BMl > 25 & $97.9 \%(46)$ & $97.4 \%(37)$ & $\mathrm{ns}$ & $88 \%(73)$ & $82.9(34)$ & $\mathrm{ns}$ \\
\hline Smoking & $59.6 \%(28)$ & $31.6 \%(12)$ & 0.010 & $56.8(46)$ & $31.7 \%(13)$ & 0.009 \\
\hline
\end{tabular}

IQR - interquartile range

Table 3. Prevalence of metabolic syndrome according to age

\begin{tabular}{|c|c|c|c|c|}
\hline & \multicolumn{2}{|c|}{ Male } & \multicolumn{2}{|c|}{ Female } \\
\hline & $\mathrm{n}(\%)$ & OR $(95 \% \mathrm{Cl})$ & $\mathrm{n}(\%)$ & OR $(95 \% \mathrm{Cl})$ \\
\hline \multicolumn{5}{|l|}{ Age } \\
\hline $18-39$ years & $47(17.6)$ & 1 & $53(15.0)$ & 1 \\
\hline $40-55$ years & $38(51.4)$ & $4.76(2.72-8.31)$ & $70(49.0)$ & $5.26(3.37-8.20)$ \\
\hline
\end{tabular}


Table 4. Gender specific comparisons of individual MS components between participants with and without MS in the Roma subgroup. Presented as median (IQR).

\begin{tabular}{|l|c|c|c|c|c|c|}
\hline \multirow{2}{*}{} & \multicolumn{2}{|c|}{ Roma men } & \multirow{2}{*}{$\boldsymbol{p}$} & \multicolumn{2}{c|}{ Roma women } & \multirow{2}{*}{$\mathbf{p}$} \\
\cline { 2 - 3 } \cline { 5 - 7 } & without MS & with MS & & without MS & with MS & \\
\hline Glu & $4.75(0.59)$ & $5.19(1.26)$ & $<0.001$ & $4.5(0.61)$ & $4.96(0.95)$ & $<0.001$ \\
\hline TG & $0.96(0.59)$ & $2.1(1.61)$ & $<0.001$ & $0.9(0.57)$ & $1.71(1.01)$ & $<0.001$ \\
\hline HDL & $1.07(0.42)$ & $0.79(0.21)$ & $<0.001$ & $1.18(0.34)$ & $0.96(0.25)$ & $<0.001$ \\
\hline Waist & $85(12)$ & $109.5(17)$ & $<0.001$ & $80(16)$ & $96(14)$ & $<0.001$ \\
\hline SBP & $121(17)$ & $136(20)$ & $<0.001$ & $113(14)$ & $131(27)$ & $<0.001$ \\
\hline
\end{tabular}

Table 5. Gender specific comparisons of age, chol., $L D L$, apoB, hsCRP, uric acid, and smoking between participants with and without MS in the Roma subgroup. Presented as median (IQR), smoking as percentage (n).

\begin{tabular}{|c|c|c|c|c|c|c|}
\hline & \multicolumn{2}{|c|}{ Roma men } & \multirow{2}{*}{$p$} & \multicolumn{2}{|c|}{ Roma women } & \multirow{2}{*}{$p$} \\
\hline & without MS & with MS & & without MS & with MS & \\
\hline Age & $30.8(14)$ & $40.4(1.59)$ & $<0.001$ & $32.9(13.0)$ & $42.4(10.3)$ & $<0.001$ \\
\hline Cholesterol & $4.47(1.11)$ & $4.9(1.07)$ & 0.037 & $4.6(1.11)$ & $5.15(1.19)$ & $<0.001$ \\
\hline LDL & $2.31(0.87)$ & $2.58(1.07)$ & ns & $2.41(0.86)$ & $2.77(0.9)$ & $<0.001$ \\
\hline ApoB & $0.69(0.3)$ & $0.84(0.36)$ & 0.001 & $0.71(0.26)$ & $0.88(0.27)$ & $<0.001$ \\
\hline hsCRP & $1.12(2.54)$ & $4.7(3.93)$ & $<0.001$ & $1.03(2.32)$ & $3.02(5.27)$ & $<0.001$ \\
\hline Uric acid & 254 (123) & $292(147)$ & 0.010 & $191(78)$ & 217 (107) & 0.003 \\
\hline Smoking & $64.0 \%(71)$ & $59.6 \%(28)$ & ns & $57.4 \%(113)$ & $56.8 \%(46)$ & ns \\
\hline
\end{tabular}

Table 6. Association of age and metabolic syndrome with hsCRP

\begin{tabular}{|l|c|c|c|c|}
\hline \multirow{2}{*}{} & \multicolumn{2}{|c|}{ Male } & \multicolumn{2}{c|}{ Female } \\
\cline { 2 - 5 } & $\mathbf{n}(\%)$ & OR $(95 \% \mathrm{Cl})$ & $\mathrm{n}(\%)$ & 1 \\
\hline Age & $25(9.4)$ & 1 & $49(14.0)$ & $1.15(0.66-2.00)$ \\
\hline 18-39 years & $19(25.7)$ & $2.01(0.97-4.15)$ & $31(22.1)$ & 1 \\
\hline 40-55 years & $18(7.0)$ & 1 & $44(11.6)$ & $3.07(1.79-5.28)$ \\
\hline MS
\end{tabular}

syndrome in both subgroups (Roma, non-Roma) independent of gender. (Fig. 1, Table 6).

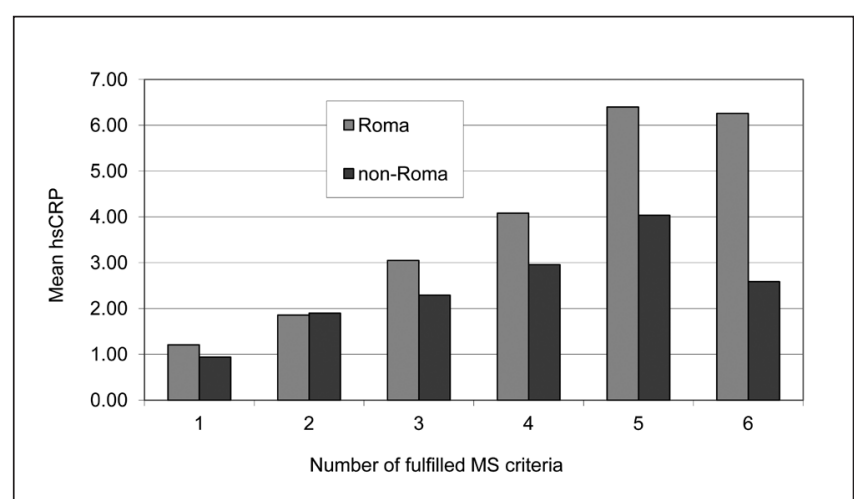

Fig. 1. Association between plasma levels of hsCRP and increasing fulfilled criteria of metabolic syndrome in the Roma and non-Roma populations.

\section{DISCUSSION}

In this study, based on younger population (to this time less studied in this community), the prevalence of obesity was significantly higher in Roma settlements. We found overweight significance for Roma women and the first grade of obesity was significant for the whole Roma study cohort (Roma men $28.8 \%$, Roma women $26.2 \%$ ) compared with the non-Roma cohort (men $20.5 \%$, women $19.6 \%$ ). Roma women had significantly higher waist circumference and body mass index overall compared with not significant findings in the male population. In this observational study we confirmed the findings from previous studies in the general cohort of Roma and non-Roma populations $(17,18)$.

We found higher prevalence of metabolic syndrome in the Roma population associated with advanced age. Nearly one-third of the Roma population fulfilled the criteria for metabolic syndrome. By selecting a subpopulation with metabolic syndrome we documented as statistically significant higher waist circumference 
for the Roma subpopulation and higher body mass index as well. Cardiovascular disease and all-causes mortality are increased in the population with metabolic syndrome, even in the absence of baseline CVD and diabetes type 2. Early identification, treatment and prevention of metabolic syndrome present a major challenge for health care professionals in the face of obesity epidemic and sedentary lifestyles (6). Abdominal obesity is the most common feature of this cluster of metabolic abnormalities, increasing the risk of coronary heart disease in type 2 diabetic patients. Obesity, however, is a heterogeneous phenotype and not every obese patient is at high risk of coronary heart disease (subgroup "fit-fat" - obese patients, but physically active), despite the fact that there is a well-established relationship between overweight/ obesity and the probability of developing complications. For instance, it has been shown that patients with abdominal obesity, high triglycerides and low HDL-cholesterol concentrations are frequently characterised by a triad of metabolic abnormalities, socalled atherogenic metabolic triad, even in the absence of type 2 diabetes (19). This finding could be also applied to the population without a previous history of CVD or diabetes.

Lipid profile analyses in the population with metabolic syndrome show that HDL cholesterol levels remain statistically lower for both Roma men and women (20). LDL cholesterol levels were not significantly higher (different) for both men and women with metabolic syndrome. We did not confirm hyperglyceamia or hypertriglyceridemia among the Roma population published in the previous study (21), which should be associated with the younger population included in this study. We believe, that such risk factors will develop in case of missing prevention strategies for Roma settlements. Surprisingly, triglycerides were significantly higher in non-Roma women with metabolic syndrome. The fact has not yet been explained, possibly lifestyle, mainly dietary habits, could be involved. However, genetical determination cannot be excluded. Some papers reported that a predisposition for metabolic syndrom starts in early age according to the composition of the mother's milk during the first five days of life (22).

Inflammation is a popular concept in preventive cardiology, and among inflammatory markers that have been examined, the acute-phase response marker C-reactive protein (measured by high sensitive technique - hsCRP) has been shown to predict the risk of future myocardial infarction beyond the contribution of traditional risk factors in both primary and secondary prevention studies and in patients with acute coronary syndromes as well (23). Levels of hsCRP were statistically significantly higher in the Roma population with metabolic syndrome, especially in Roma men. Plasma levels of hsCRP were not in correlation with age but were associated with the increasing number of fulfilled criteria for metabolic syndrome; this may be possible explanation for the increased CVD morbidity and mortality among Roma compared with non-Roma. Ginter et al. reported that premature/ untimely cardiovascular mortality occurred more than 2.5 times more frequently among male Roma than among the average males in the Slovak population (12).

Finally, we can conclude that higher rates of obesity, metabolic syndrome itself, smoking, and low HDL cholesterol were found among residents of Roma settlements. This higher prevalence of CVD risk factors along with perceived barriers to health care may lead to increased CVD morbidity and mortality in elderly Roma compared with non-Roma (24). Therefore, there is a need for early prevention in this minority population as well as for changes in the provision of health care services. To confirm this data, prospective trials in Roma settlements should be performed.

This study has several limitations. The cross-sectional design of the study did not allow us to follow the patients prospectively. Furthermore, only patients younger than 55 years were included, nevertheless, the incidence of metabolic syndrome is higher in older patients.

\section{CONCLUSION}

Our study confirmed the higher prevalence of obesity and metabolic syndrome as well as the higher prevalence of CV risk factors associated with metabolic syndrome among the younger Roma population, which may be the cause of increased CVD morbidity and mortality rates among the Roma elderly compared with non-Roma.

\section{Acknowledgement}

This work was partially supported by the Agency of the Slovak Ministry of Education for the Structural Funds of EU CEMIO-ITMS: 26220120058 (30\%), the project VEGA grant 1/1072/12, a grant of Visegrad fund, and by Roche Slovensko, s. r. o. This paper was also partially funded within the framework of the project "Social determinants of health in socially and physically disadvantaged and other groups of population" (CZ.1.07/2.3.00/20.0063).

\section{Conflict of Interests}

None declared

\section{APPENDIX}

HepaMeta Team: Peter Jarčuška, Andrea Madarasová Gecková, Mária Mareková, Daniel Pella, Leonard Siegfried, Pavol Jarčuška, Lýdia Pastvová, Ján Fedačko, Jana Kollárová, Peter Kolarčik, Daniela Bobáková, Zuzana Veselská, Ingrid Babinská, Sylvia Dražilová, Jaroslav Rosenberger, Ivan Schréter, Pavol Kristián, Eduard Veseliny, Martin Janičko, Ladislav Virág, Anna Birková, Marta Kmet’ová, Monika Halánová, Darina Petrášová, Katarína Cáriková, Viera Lovayová, Lucia Merkovská, Lucia Jedličková, Ivana Valková

\section{REFERENCES}

1. Reaven GM. Banting lecture 1988. Role of insulin resistance in human disease. Diabetes. 1988 Dec;37(12):1595-607.

2. Liese AD, Mayer-Davis EJ, Haffner SM. Development of the multiple metabolic syndrome: an epidemiologic perspective. Epidemiol Rev. 1998;20(2):157-72.

3. Isomaa B, Almgren P, Tuomi T, Forsén B, Lahti K, Nissén M, et al. Cardiovascular morbidity and mortality associated with the metabolic syndrome. Diabetes Care. 2001 Apr;24(4):683-9.

4. Alexander CM, Landsman PB, Teutsch SM, Haffner SM; Third National Health and Nutrition Examination Survey (NHANES III); National Cholesterol Education Program (NCEP). NCEP-defined metabolic syndrome, diabetes, and prevalence of coronary heart disease among NHANES III participants age 50 years and older. Diabetes. 2003 May;52(5):1210-4. 
5. Hunt KJ, Resendez RG, Williams K, Haffner SM, Stern MP; San Antonio Heart Study. National Cholesterol Education Program versus World Health Organization metabolic syndrome in relation to all-cause and cardiovascular mortality in the San Antonio Heart Study. Circulation. 2004 Sep 7;110(10):1251-7.

6. Lakka HM, Laaksonen DE, Lakka TA, Niskanen LK, Kumpusalo E, Tuomilehto J, et al. The metabolic syndrome and total and cardiovascular disease mortality in middle-aged men. JAMA. 2002 Dec 4;288(21):270916.

7. Grundy SM, Hansen B, Smith SC Jr, Cleeman JI, Kahn RA; American Heart Association; National Heart, Lung, and Blood Institute; American Diabetes Association. Clinical management of metabolic syndrome: report of the American Heart Association/National Heart, Lung, and Blood Institute/American Diabetes Association conference on scientific issues related to management. Circulation. 2004 Feb 3;109(4):551-6.

8. National Cholesterol Education Program (NCEP) Expert Panel on Detection, Evaluation, and Treatment of High Blood Cholesterol in Adults (Adult Treatment Panel III). Third Report of the National Cholesterol Education Program (NCEP) Expert Panel on Detection, Evaluation, and Treatment of High Blood Cholesterol in Adults (Adult Treatment Panel III) final report. Circulation. 2002 Dec 17;106(25):3143-421.

9. Ridker PM, Pradhan A, MacFadyen JG, Libby P, Glynn RJ. Cardiovascular benefits and diabetes risks of statin therapy in primary prevention: an analysis from the JUPITER trial. Lancet. 2012 Aug 11;380(9841):565-71.

10. Baker D, Mead N, Campbell S. Inequalities in morbidity and consulting behaviour for socially vulnerable groups. Br J Gen Pract. 2002 Feb;52(475):124-30.

11. Cappuccio FP. Ethnicity and cardiovascular risk: variations in people of African ancestry and South Asian origin. J Hum Hypertens. 1997 Sep;11(9):571-6.

12. Ginter E, Krajcovicova-Kudlackova M, Kacala O, Kovacic V, Valachovicova M. Health status of Romanies (Gypsies) in the Slovak Republic and in the neighbouring countries. Bratisl Lek Listy. 2001;102(10):479-84.

13. Vaňo B. The Demographic characteristics of Roma population in Slovakia. Bratislava: INFOSTAT; 2001.

14. Koupilová I, Epstein H, Holčík J, Hajioff S, McKee M. Health needs of the Roma population in the Czech and Slovak Republics. Soc Sci Med. 2001 Nov;53(9):1191-204.
15. Alberti KG, Zimmet P, Shaw J. Metabolic syndrome - a new world-wide definition. A Consensus Statement from the International Diabetes Federation. Diabet Med. 2006 May;23(5):469-80.

16. Madarasová Gecková A, Jarčuška P, Mareková M, Pella D, Siegfried L, Jarčuška P, et al.; HepaMeta Team. HepaMeta - Prevalence of hepatitis $\mathrm{B} / \mathrm{C}$ and metabolic syndrome in population living in separated and segregated Roma settlements: a methodology for a cross-sectional populationbased study using community-based approach. Cent Eur J Public Health. 2014 Mar;22 Suppl:S6-11.

17. Mackenbach JP, Stirbu I, Roskam AJ, Schaap M, Menville G, Leinsalu $\mathrm{M}$, et al. Socio-economic inequalities in mortality and morbidity: a cross-European perspective. In: Tackling health inequalities in Europe: an integrated approach. Eurothine: final report. Rotterdam: Department of Public Health, University Medical Centre Rotterdam; 2007. p. 24-48.

18. Carrasco-Garrido P, López de Andrés A, Hernández Barrera V, JiménezTrujillo I, Jiménez-García R. Health status of Roma women in Spain. Eur J Public Health. 2011 Dec;21(6):793-8.

19. Lemieux I, Pascot A, Almeras, N. Obesity in the 21(st) century: new approaches? Ann Endocrinol (Paris). 2001;62(4):255-61.

20. Vozarova de Courten B, de Courten M, Hanson RL, Zahorakova A, Egyenes HP, Tataranni PA, et al. Higher prevalence of type 2 diabetes, metabolic syndrome and cardiovascular diseases in gypsies than in nongypsies in Slovakia. Diabetes Res Clin Pract. 2003 Nov;62(2):95-103.

21. Ostrihoňová T, Bérešová J. Occurrence of metabolic syndrome and its risk factors amongst a selected group of Roma inhabitants. Hygiena 2010;55(1):7-14. (In Slovak.)

22. Krcho P, Bazárová J, Dihenešč́ková D. Composition of the mother milk during the first five days in low and high risk population. Acta Med Port. 2012;25 Suppl 2:163.

23. Lemieux I, Pascot A, Prud'homme D, Alméras N, Bogaty P, Nadeau A, et al. Elevated C-reactive protein: another component of the atherothrombotic profile of abdominal obesity. Arterioscler Thromb Vasc Biol. 2001 Jun;21(6):961-7.

24. Jarcuska P, Bobakova D, Uhrin J, Bobak L, Babinska I, Kolarcik P, et al.; HEPA-META team. Are barriers in accessing health services in the Roma population associated with worse health status among Roma? Int J Public Health. 2013 Jun;58(3):427-34. 